Editorial

\title{
Political Trade-Offs: Democracy and Governance in a Changing World
}

\author{
Todd Landman ${ }^{1, *}$ and Hans-Joachim Lauth ${ }^{2}$ \\ ${ }^{1}$ School of Politics and International Relations, University of Nottingham, Nottingham, NG7 2RD, UK; \\ E-Mail: todd.landman@nottingham.ac.uk \\ ${ }^{2}$ Chair of Comparative Politics and German Government, University of Wuerzburg, 97074 Wuerzburg, Germany; \\ E-Mail: hans-joachim.lauth@uni-wuerzburg.de \\ * Corresponding author
}

Submitted: 14 November 2019 | Published: 25 November 2019

\begin{abstract}
The investigation of trade-offs in political science receives only limited attention, although many scholars acknowledge the importance of trade-offs across a variety of different areas. A systematic and comprehensive examination of the topic is missing. This thematic issue of Politics and Governance sheds light on this research deficit by providing a holistic but also an integrative view on trade-offs in the political realm for the first time. Researchers of trade-offs from different political areas present and discuss their findings, and promote a fruitful exchange, which overcomes the current isolation of the approaches. They consider the theoretical and methodological questions as well as the identification of empirical tradeoffs. Furthermore, they provide insights into the possibility to balance trade-offs and strategies, which could help actors to find such compromises.
\end{abstract}

\section{Keywords}

balancing trade-offs; constructed trade-offs; logical trade-offs; trade-offs

\section{Issue}

This editorial is part of the issue "Trade-Offs in the Political Realm: How Important Are Trade-Offs in Politics?" edited by Todd Landman (University of Nottingham, UK) and Hans-Joachim Lauth (University of Wuerzburg, Germany).

(C) 2019 by the authors; licensee Cogitatio (Lisbon, Portugal). This article is licensed under a Creative Commons Attribution 4.0 International License (CC BY).

Trade-offs are central to economics, as they are to life. They are at the heart of economics because neither the decision-maker nor society can have everything it wants. We look at the trade-offs that must be made when the criteria that are used to govern social decisions cannot all be fully satisfied. (Campbell \& Kelly, 1994, p. 422)

\section{Introduction}

Trade-offs play an important role not only in the economy, but also in politics and society. Many scholars acknowledge the importance of trade-offs across a variety of different areas: (1) ecology vs. economy (Inglehart, 1977); (2) democratic functions (responsibility vs. responsiveness) and the quality of democracy (Campbell, 2019; Diamond \& Morlino, 2004; Lauth, 2016); (3) efficiency of electoral systems and representative gov- ernment (Nohlen, 1996); (4) majoritarian and consensus democracy and the representation of interests (Ganghof, 2018; Lijphart, 2012); (5) freedom and security in times of terrorism (Brysk \& Shafir, 2007; Hidalgo, 2009); (6) economic abundance and political freedom (Landman, 2013); (7) truth and justice (Landman, 2013); (8) the "dilemma" (Smilov, 2008) between libertarian and egalitarian political finance models; and (9) the many trade-offs evident in the Brexit negotiations between the EU and the UK since the 2016 Referendum.

Such an enumeration could be extended ad nauseam; however, these examples highlight that perfect solutions are likely not to be available, and that the choices made by societies and/or political actors have consequences in the form of serious and unavoidable opportunity costs. Given the ubiquity and relevance of tradeoffs in the political realm, the understanding of the phenomenon of trade-offs remains undertheorized and is 
particularly thin empirically, which reveals a significant gap in research. In addition, often the concept of tradeoffs remains unclear: Is it a logical trade-off between two goals such that each cannot be realized at the same time under any circumstances, or is the trade-off simply constructed? The trade-off between effectiveness and participation in democracy (Dahl, 1994), which processes of deliberation might resolve may be such a case of a constructed trade-off. Other authors discuss in a similar way the relationship between input and output legitimacy (Lindgren \& Persson, 2011).

This thematic issue of Politics and Governance sheds new light on this deficit in research by providing an integrative view on trade-offs in the political realm. The collection of articles brings together researchers of tradeoffs from different political areas to promote a fruitful set of exchanges, which we believe overcome the current isolation of many different approaches. The contributions deal with trade-offs in politics across three different perspectives:

1. Conceptually: What are the specific trade-offs in the political area, how can we conceptualize and identify them? How can we distinguish between a logical trade-off and relationship between two things that merely appear to be a trade-off?

2. Methodologically: How can we assess trade-offs and their mutual and interdependent relationships?

3. Empirically: Which research findings exist and how relevant are trade-offs in the political realm? How possible is it to balance trade-offs? Which strategies help actors find such compromises? How do empirical findings differ from logical trade-offs?

The majority of the contributions address empirical questions and look for improvement in balancing these kinds of trade-offs. Ganghof (2019) analyses the trade-offs involved in the design of different democratic institutions with a particular focus on simple and complex majoritarian systems. He shows how mixed parliamentary systems with some degree of separation of powers are superior to pure parliamentary systems for reaching the compromises needed for effective democratic governance. Ganghof (2019) argues further that presidential systems are less able to navigate the challenges of majoritarianism and avoid inter-branch deadlock than parliamentary systems. Nilsson and Weitz (2019) consider the implementation of the United Nations Sustainable Development Goals and offer a program that ensures more coherent, relevant, and effective policy outputs. The 2030 Agenda does not fundamentally change the dynamic of trade-offs in politics, but with its wide scope, many interactions, and guiding principles of universality, integration and transformative change, it provides for greater challenge and a more difficult landscape of tradeoffs than in the past. The authors thus look for some form of standard that can inform or induce the design of poli- cies to identify, address, and mitigate trade-offs far as possible. Nilsson and Weitz (2019) discuss the treatment of trade-offs in the input, process and output stages of policy-making to improve the governance infrastructure, which not only generates the much needed a priori understanding for policy-makers around the character of trade-offs, but also paves the way for more effective approaches in the latter two stages.

Swe and Lim (2019) analyze the quality of public services in Myanmar as a function of different modes of governance. They compare the trade-offs between and among three public service values of efficiency, effectiveness, and equity, which cannot all be achieved at the same time. Their different modes of governance at the local level include hierarchy, market, and network, the combination of which affect the delivery of public services in the area of agriculture. For them, the initial contradictions among efficiency, effectiveness, and equity in systems of network governance are overcome as the network matures, while market governance systems see a reverse in this logic, leading to greater contradictions over time.

Landman and Silverman (2019) investigate the tradeoffs between globalization and modern slavery. They compare the positive and negative arguments surrounding the economic and political dimensions of globalisation with respect to their possible effect on the prevalence of modern slavery. Using a cross-national data set covering 70 countries, they show that countries with higher degrees of economic globalisation and better democratic and legal institutions tend to have lower levels of slavery prevalence. These findings are upheld even after taking into account other explanatory variables such as violent conflict and regional differentiation. In similar fashion, Wiesner (2019) addresses the trilemma associated with globalisation and the EU: (1) free trade; (2) democratic and social standards; and (3) national sovereignty. Wiesner (2019) argues that it is not possible to achieve all three in the context of the EU, while her solution is to strengthen democratic and social standards while maintaining liberal trade orientation and reducing national sovereignty.

Kraus et al. (2019) examine peacemaking with a particular focus on third party interventions and the tradeoffs between human rights and the need to find agreement between contending political actors. Their conceptual framework seeks to transcend this binary trade-off through focussing on problem perception and strategy appraisals using the cases of peacemaking in Myanmar, Thailand, and Ukraine. The framework includes existing problem-solving strategies (e.g., sequencing and instrumentalization) and lesser known strategies (e.g., compartmentalization and utilization) to provide meaningful ways to synthesise creative thinking and benefits for third party peace interventions.

Hidalgo (2019) offers a strongly theoretical and conceptually grounded contribution. He uses the concept of trade-offs as an approach for political discussion and demonstrates to what extent the conceptualisation of 
democratic antinomies and the notion of value tradeoffs could be seen as 'communicating vessels.' His argument is that democracy is defined by several antinomies that are irreducible in theory and therefore require trade-offs in political practice (e.g., freedom and security, economic growth and sustainability, and democracy and populism). Hidalgo (2019) argues that the success of democratic institutions depends on the balance of the necessarily conflicting principles of democracy.

Schlenkrich (2019) provides a methodological contribution on measuring trade-offs in democracy research. Like Hidalgo (2019), he understands democracy as a multidimensional concept whose central dimensionspolitical freedom, political equality and political and legal control-cannot all be developed comprehensively at the same time. With the help of a reformulated data set from the Varieties of Democracy project, Schlenkrich (2019) shows that trade-offs that are assumed theoretically appear in empirical findings that demonstrate corresponding profiles of democracy.

\section{Conception and Identification of Trade-Offs}

The contributions in this issue explore different themes relating to the idea of trade-offs in varying degrees, where their different understandings reveal similarities and significant differences. It is thus appropriate to deepen conceptual considerations. It is often not possible to accomplish all beneficial political goals at the same time. Trade-offs are inevitable: Achieving the benefit of one political goal comes necessarily at the expense of another political goal, challenging the rather simple and linear views of 'the more the better' or 'all good things go together.' Societies and/or political actors must restrict themselves and decide which political aims they value higher: "choices must be made, sometimes tragic losses accepted in the pursuit of some preferred ultimate end" (Berlin, 2000, p. 23). Even though it is possible to balance these different objectives in a compromise, the idea of seeking a maximum benefit for all options is abandoned.

Hidalgo (2019) uses many terms that appear analogous to trade-offs (e.g., dilemmas, significant paradoxes, aporias, and antinomies), but he proposes a useful definition of trade-offs:

A trade-off is popularly known as a situational decision that involves the gaining or growing of one quality or quantity concerning a certain set or amount in return for simultaneously losing or diminishing qualities or quantities in different aspects. Similar to the figure of a reciprocal or inverse proportionality, a tradeoff is often compared with a zero-sum game, in which each gain or loss of one actor's or group's utility is balanced or compensated by the gains or losses of other actors or groups. Thus, in simple terms, a tradeoff is commonly observed, whenever the increasing of one thing is accompanied by the decreasing of another. (p. 267)
This definition is similar to that offered by Lauth and Schlenkrich $(2018$, p. 82) in their consideration of democracy: "a trade-off is an irresolvable connectedness between two inverse effects of one institution regarding two dimensions. This trade-off expresses two contrasting but normative equally weighted democracy conceptions to which the selected institutions belong." As Hidalgo points out, the authors assume that the dimensions of liberty and equality belong to the core understanding of democracy and that a limitation of one of them would lead to a deficient form of democracy. Equally, Diamond and Morlino (2004, p. 21) describe the idea of trade-offs within the realm of democracies: "it is impossible to maximize all [dimensions] at once. [Every] democratic country must make an inherently value-laden choice about what kind of democracy it wishes to be." For a supporter of a libertarian understanding of democracy, however, there would be no trade-off situation. In contrast, and more generally but focused on freedom and equality as well, Berlin's value pluralism claims that the "world...is one which we are faced with choices between ends equally ultimate, and claims equally absolute, the realization of some of which must inevitably involve the sacrifice of others" (Berlin, 1969, p. 168).

Kraus et al. (2019) specify their ideas of trade-offs in demarcation from dilemmas:

We understand a dilemma as a standoff between two or more imperatives ( $A$ vs. B) that are perceived as equally compulsory but not attainable at the same time, leaving only either-or options. A trade-off is understood as a balancing of two or more imperatives (A vs. B) that are perceived as similarly compulsory and opposed, but partly satisfiable at the same time by exchanging one thing in return for another. Both, dilemma and trade-off, can arise from normative and pragmatic claims. (p. 333)

The distinction is based on the fact that dilemmas describe a situation in which one is forced to choose between two equally unpleasant things (e.g., prisoner's dilemma: betrayal of the accomplice or high prison sentence). There is no possibility of a gradual mediation. Thus, decision situations that are binomial (yes vs. no) are addressed. Trade-offs are decision situations (also unavoidable) that allow gradual decision making and are therefore capable of compromise. Balancing is possible. This probably includes most of the points of contention in political disputes, but not cases that make normative claims to truth.

A central question arises in the clarification of the ontological status of trade-offs. Are these essential-as in the pointed understanding of freedom and equality-or are they constructed conflicts? The latter claims, for example, the idea of a green economy, in which the contradiction between economy and sustainability is eliminated and the trade-off situation would be thus resolved. Inglehart (1977) has maintained the idea of a trade-off 
between materialist and postmaterialist values by incorporation it into the methodological conception of value change research. In his empirical studies, he compiled the catalogue of questions on the ranking, which requires 'either or decisions.' Critics, however, called for the use of rating, which allows different preferences to be weighted equally. Thus, unsolvable trade-offs should be referred as solvable or dissolvable trade-offs. For a further and deeper discussion of ranking and rating, see Hino and Imai (2019).

In addition to a theoretical debate, the empirical investigation is a good test of whether a trade-off exists or not (e.g., Landman \& Silverman, 2019). This makes it possible to answer the question of whether there is only an apparent trade-off. Landman and Silverman (2019) show that critics argue that modern slavery is the 'dark underbelly' of globalisation, and yet their empirical analysis demonstrates that more open societies have lower levels of slavery prevalence.

The constructivist perspective allows a different approach to understanding of trade-offs. These depend on the perception of the participants whether a trade-off situation exists or not. An almost classic case is the already mentioned tension between economy vs. sustainability (preservation and protection of the environment). This is understood both as an insurmountable contradiction or as a mediable conflict of interests (green economy). In this example, some aspects can be clarified by including scientific facts (such as the human contribution to global warming). However, the connection between these two huge concepts is extremely complex and can only be determined definitively in this way to a limited extent.

The research situation changes when not only facts, but their interpretation is decisive for the understanding of the relationship of tension. In this case, the question arises whether the interpretation can be changed or how Kraus et al. (2019) formulate in their contribution can be re-framed. They comprehend this reframing from a cognitive constructivist point of view:

Holding a cognitive constructivist point of view, we consider dilemmas and trade-offs as perception patterns created by reference frames such as ideas, practices, narratives, goals, values, emotions, and beliefs (Goffman, 1986; Lakoff \& Wehling, 2016). Frames are key codes for making sense of the world and thus tend to resist change; when their premises are incommensurable, compete, or collide, a dilemma or trade-off is the result. Like the frames themselves, the perception patterns of dilemmas are contingent: Some people see dilemmas and trade-offs where others-with other contexts and histories-do not (Acharya, 2004; Harding, 2017). (Kraus et al., 2019, p. 334)

For example, the relationship between France and Germany from 1914 to 1945 was often seen as antagonistic, leaving little room for reconciliation. This friendenemy thinking, however, changed in the reconciliation process after the Second World War, which succeeded in decisively changing the hostile narrative. Such strategies make sense when it comes to conflict resolution, as in this case. However, they do not cover all possible tradeoff constellations especially when it comes to the clarification of facts. Thus, such a reframing strategy would ultimately lead to a postfactual view of facts that does not solve any problems. Finally, Kraus et al. (2019) emphasise likewise the difficulty to change frames, which are inescapably linked to unconscious thinking habits, worldviews, existential experiences, and social identity.

Such a constructivist view can, however, also lead to the obscuring of conflicting interests and conflicting goals, as McShane et al. (2011), in their critical contribution to problems of win-win rhetoric, point out. They describe, how a 'win-win language' has become common among important international organizations to characterise the simultaneous achievement of positive conservation and development outcomes. The use of this language can be observed also in other policy discourse, for example regarding the link between the environment and poverty reduction. In their research on the relationship between conservation and development, however, they cannot discover a win-win situation. On the other hand, they argue for the opposite to be named accordingly:

In our experience, the real power of the trade-off concept comes in its ability to bring diverse actors to the common recognition-one not forthcoming when problems are framed as win-win-that hard choices are being faced. Choices, because there are different options, each with their own suite of possible outcomes with respect to human well-being as well as the diversity, functioning and services provided by ecosystems over space and time (Millennium Ecosystem Assessment, 2005). Hard, because each choice-even the best or "optimal" one-involves loss in some way; a loss that for at least some of those affected is likely to be a significant one. Hard choices in the conservation-development nexus are due to a variety of reasons. (McShane et al., 2011, p. 968)

The authors see emerging a new challenge and task for research; conservationists have to find ways to identify and explicitly acknowledge the trade-offs and hard choices that are involved. The discussion of the constructivist research perspective shows a surprising ambivalence. While on the one hand reframing can help to balance trade-offs and defuse conflicts, on the other it leads to the concealment of opposites and also to fake news or postfactual news, in which real contradictions are obscured.

\section{Conclusion}

Across a wide range of different political arenas and policy area, this collection of contributions shows that trade- 
offs are alive and well. They also show, however, that many can be transcended logically, or can be shown to be falsely constructed empirically. We agree that fundamentally a real trade-off involves the sacrifice of one political goal to achieve another, where any notion of compromise is not possible. So we define a trade-off as a decision-making situation about two goals, which according to the perception of the decision-makers cannot be comprehensively realized at the same time. Two basic forms can be distinguished: On the one hand, trade-offs are logically constituted and cannot be cancelled; on the other hand, if they are identified as constructed, they can ultimately be transferred. Even if a comprehensive simultaneous realization of goals is not possible, they can still be balanced if both goals are to be maintained. There are three tasks for research: The first is to clarify what type of trade-off exists. This identification requires both theoretical and empirical research. On the other hand, there is the normative task of determining which goal should be pursued if a hard choice situation exists. If a mediation or balancing of the goals is possible, appropriate solution strategies would have to be formulated.

The ability of scientific contributions to solve or balance different kinds of trade-offs has been well demonstrated by the various contributions in this thematic issue. We hope that the thematic issue as a whole has also been able to outline research strategies to deal productively with the sketched problems.

\section{Acknowledgments}

The authors would like to thank all the anonymous reviewers of this thematic issue who have contributed strongly to strengthen and to improve the quality of the articles.

\section{Conflict of Interests}

The authors declare no conflict of interests.

\section{References}

Berlin, I. (1969). Four essays on liberty. Oxford: Oxford University Press.

Berlin, I. (2000). The power of ideas. Princeton, NJ, and Oxford: Princeton University Press.

Brysk, A., \& Shafir, G. (Eds). (2007). National insecurity and human rights: Democracies debate counterterrorism. Berkeley, CA: University of California Press.

Campbell, D. E., \& Kelly, J. S. (1994). Trade-off theory. The American Economic Review, 84(2), 422-426.

Campbell, D. F. J. (2019). Global quality of democracy as innovation enabler: Measuring democracy for success. New York, NY: Palgrave Macmillan.

Dahl, R. (1994). A democratic dilemma: System effectiveness versus citizen participation. Political Science Quarterly, 109(1), 23-34.

Diamond, L. J., \& Morlino, L. (2004). The quality of democracy: An overview. Journal of Democracy, 15(4), 20-31.

Ganghof, S. (2018). A new political system model: Semi-parliamentary government. European Journal of Political Research, 57(2), 261-281.

Ganghof, S. (2019). Designing democratic constitutions: The search for optimality. Politics and Governance, 7(4), 243-253.

Hidalgo, O. (2009). Democratic antinomies: Freedom and security, liberty and equality, individual and collective claims. In H. Motoh \& L. Skof (Eds.), Proceedings to the conference freedom and democracy: European perceptions, European perspectives (pp. 21-31). Ljubljana: Poligrafi.

Hidalgo, O. (2019). The theory of democratic antinomies and the identification of value trade-offs in political practice. Politics and Governance, 7(4), 264-274.

Hino, A., \& Imai, R. (2019). Ranking and rating: Neglected biases in factor analysis of postmaterialist values. International Journal of Public Opinion Research, 31(2), 368-381. https://doi.org/10.1093/ijpor/edy007

Inglehart, R. (1977). The silent revolution: Changing values and political styles among Western publics. Princeton, NJ: Princeton University Press.

Kraus, A. I., Frazer, O., Kirchhoff, L., Kyselova, T., Mason, S. J. A., \& Federer, J. P. (2019). Dilemmas and trade-offs in peacemaking: A framework for navigating difficult decisions. Politics and Governance, 7(4), 331-342.

Landman, T. (2013). Human rights and democracy: The precarious triumph of ideals. London: Bloomsbury.

Landman, T., \& Silverman, B. W. (2019). Globalization and modern slavery. Politics and Governance, 7(4), 275-290.

Lauth, H.-J. (2016). The internal relationships of the dimensions of democracy: The relevance of tradeoffs for measuring the quality of democracy. International Political Science Review, 37(5), 606-617. https://doi.org/10.1177/0192512116667630

Lauth, H.-J., \& Schlenkrich, O. (2018). Making tradeoffs visible: Theoretical and methodological considerations about the relationship between dimensions and institutions of democracy and empirical findings. Politics and Governance, 6(1), 78-91. https:// doi.org/10.17645/pag.v6i1.1200

Lijphart, A. (2012). Patterns of democracy: Government forms and performance in thiryt-six countries. New Haven, CT: Yale University Press.

Lindgren, K.-O., \& Persson, T. (2011). Input and output legitimacy: Synergy or trade-off? Empirical evidence from an EU survey. Journal of European Public Policy, 17(4), 449-467.

McShane, T. O., Hirsch, P. D., Trung, T. C., Songorwa, A. N., Kinzig, A., Monteferri, B., . . . \& Welch-Devine, M. (2011). Hard choices: making trade-offs between biodiversity conservation and human well-being. Biological Conservation, 144(3), 966-972.

Nilsson, M., \& Weitz, N. (2019). Governing trade-offs and building coherence in policy-making for the 2030 
agenda. Politics and Governance, 7(4), 254-263.

Nohlen, D. (1996). Elections and electoral systems. New Delhi: Friedrich-Ebert-Stiftung.

Schlenkrich, O. (2019). Identifying profiles of democracies: A cluster analysis based on the democracy matrix dataset from 1900 to 2017. Politics and Governance, $7(4), 315-330$.

Smilov, D. (2008). Dilemmas for a deregulation of money and politics (DISC Working Paper Series, No. 2008/4).
Budapest: Center for the Study of Imperfections in Democracies. Retrieved from https://bit.ly/2QhulMk Swe, Y. L. W., \& Lim, S. (2019). Associations between the mixture of governance modes and the performance of local public service delivery. Politics and Governance, 7(4), 301-314.

Wiesner, C. (2019). Free trade versus democracy and social standards in the European Union: Trade-offs or trilemma? Politics and Governance, 7(4), 291-300.

\section{About the Authors}

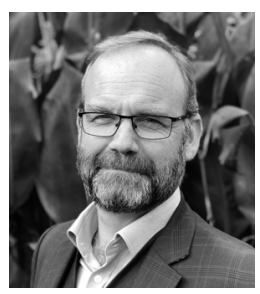

Todd Landman (FRSA) is Professor of Political Science in the School of Politics and International Relations, Pro Vice Chancellor of the Faculty of Social Sciences, and Executive Director of the Rights Lab at the University of Nottingham. He is author of numerous research monographs, articles, and reports on the systematic analysis of development, democracy, and human rights. He has carried out a large number of international consultancy projects for governmental and non-governmental organisations.

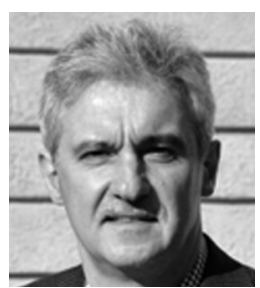

Hans-Joachim Lauth is Professor for Comparative Politics and German Government at the Institute for Political Science and Sociology, University of Wuerzburg, since 2008. He received his PhD at the University of Mainz in 1991. In 2002 he finished his second book (Habilitation) about democratic theory and measuring democracy. His current topics of research concern democracy, informal institutions, rule of law and separation of powers (accountability), civil society, local self-regulation, and comparative methods. 